\title{
Analysis on the Practical Necessity of Carrying out "Education proud of Daqing City"
}

\author{
Wei Su \\ Heilongjiang Bayi Agricultural University, NO.5 Xinfeng Road, Daqing, China
}

Keywords: Education proud of Daqing City; economic transformation; the brain drain

Abstract: 2019 is the 40th anniversary of Daqing City. Looking back 40 years, Daqing City has created great material wealth and provided irreplaceable power support for the industrial development of New China; the spirit of Daqing and Iron Man formed in the process of development and construction of Daqing Oilfield has become an important part of the spirit of the Chinese nation, encouraging the Chinese people to continue to forge ahead. Carrying out "Education proud of Daqing City" is not only the historical necessity of summing up Daqing's brilliant achievements, but also the realistic need of Daqing city to realize economic transformation and development, and the direct motivation is to reverse the serious trend of college graduates' outflow from Daqing.

\section{Introduction}

In the past 60 years, generations of Daqing people have worked hard to build the largest oil production base in China on the everlasting wasteland. The outstanding contribution of Daqing Oilfield has been engraved on the historical monument of the great motherland. Looking back at Daqing Oilfield for 60 years, it is a history of hard work and brilliant achievements in entrepreneurship, and a history of struggle to fully develop the spirit to overcome difficulties and meet challenges. "In the past 60 years, Daqing Oilfield has produced 2.39 billion tons of crude oil, accounting for more than 40 percent of the country's land crude oil production in the same period, with a total of 2.9 trillion yuan in taxes and fees and various funds."[1] It should be said that Daqing Oilfield has supported the industrial development of New China for more than half a century, and once resounded through the national "Learn from Daqing in industry" is the pride of several generations of Daqing oil workers. In the new era, facing the factors such as long-term low global oil prices, increasing downward pressure on the economy and difficulties in industrial restructuring, daqing city is not self-contained, lying on the credit book, but "go all out to grasp development, promote reform, improve the environment, benefit people, change style, push daqing comprehensive revitalization, accelerate the national resource-based city transformation and development vanguard." [2]

\section{Analysis on the Practical Necessity}


Looking back at history, Daqing is full of honor; looking forward to the future, there is still a long way to go. In order to speed up the economic transformation of Daqing City and achieve high quality development, it is necessary to carry out "Education proud of Daqing City". The so-called "Education proud of Daqing City" refers to the special education activities in which the educatees understand Daqing, love Daqing and aspire to build Daqing through the educational channels of propaganda and guidance, theoretical explanation, theme education and social practice, which are full of contents, flexible ways and novel means.

\subsection{The development of "education proud of Daqing city" is a historical necessity for Daqing to sum up the historical achievements and to unite the officers' entrepreneurial hearts}

In September 1959, on the eve of the tenth anniversary of the founding of New China, Songji Mitsui jet Industrial Oil, located in Songliao Basin, and this marks the birth of Daqing Oilfield. After 60 years of development and construction, Daqing oil field has more than 70,000 oil wells, producing nearly 2.4 billion tons of crude oil, creating a rare 27-year high and stable production of more than 50 million tons in the history of the world oil industry, and then 12 consecutive years of production of more than 40 million tons of crude oil, creating China's petroleum industry construction field of many first, such as crude oil production first, crude oil recovery first, the first payment of profits and taxes. The discovery and production of Daqing oil field made New China take off the hat of "oil-poor country" in one fell swoop, and provided continuous impetus for the launch and advance of the huge economic ship of New China. "In 2018, Daqing achieved a regional GDP of 280 billion yuan, about a fifth of Heilongjiang Province, with industrial added value of 140 billion yuan and about 1/2 of Heilongjiang Province, and Daqing is still an important engine for the development of the province.” [3] In the past 60 years, Daqing Oilfield has adhered to the road of independent innovation industry serving the country, won the National Science and Technology Progress Special Award 3 times, and the overseas market revenue exceeded the 10 billion yuan mark in 2018.

Daqing Oilfield in the creation of huge material wealth, but also accumulated to form a valuable spiritual wealth. "Daqing oilfield development and construction history, is a national glory for the spirit of growth history, a Chinese self-reliance, hard-working history of entrepreneurship, but also a history of China's petroleum industry independent innovation, continuous innovation of scientific and technological progress ." [4] Sixty years ago, with the efforts of several generations of oil workers, the wilderness became the world's leading modern oil field, and the spirit of Daqing and Iron Man formed in this process became an important part of the spirit of the Chinese nation, inspiring generations of Chinese people to make great efforts and win honor for the country.

Daqing City is a young city, only 40 years to build the city, but Daqing is definitely a heroic city, several generations of "Iron Man" emerged here, inspired several generations of oil workers here to make contributions. "Ironman Jinxi Wang" is the most well-known and influential representative of oil workers in Daqing Oilfield ," prefer to live less than 20 years, desperately to win the big oil field "shows the strong will and drive of oil workers ." this difficulty, that difficulty, the state oil shortage is the biggest difficulty; this contradiction, that contradiction, state construction and other oil use is the most important contradiction" fully reflects the oil workers bear the burden of patriotism. Qimin Wang, known as "Iron Man in the New era ", has created great achievements in the field of petroleum science and technology, which provides scientific and technological support for the high and stable production of Daqing Oilfield for many years. "Better willing to work hard, but also to make the oil field stable production and high yield" not only reflects the "iron man spirit" in the new era of inheritance, but also shows the new era of oil workers' scientific and technological 
responsibility and confidence. Therefore, Qimin Wang was awarded the title of "vanguard of reform" at the 40th anniversary of reform and opening up, and the national honorary title of "model of the people" at the 70th anniversary of the founding of the people's Republic of China.

By systematically combing and summing up Daqing's historical achievements in economic construction and spiritual culture, the countless economic miracles and precious spiritual and cultural wealth created by Daqing in the past six decades have been passed on and transformed into the historical accumulation and cultural gene, spiritual strength and emotional destination of Daqing's building on the past six decades to open a new chapter of high-quality development, which can better unite people, gather talents and gather strength.

\subsection{The development of "education proud of Daqing city" is a realistic need for Daqing to accelerate economic transformation and achieve high-quality development}

For many years, Daqing City has been committed to exploring the economic transformation and development, changing the oil economy a pillar of the industrial structure, after many years of efforts, outstanding achievements. The ratio of oil to non-oil economy was 70:30 in 2004 and 30:70 in 2018, which basically achieved a overturnning.

As a typical resource and energy city, Daqing City is born of oi.the construction of "hundred years oil field" is Daqing oil workers made a solemn commitment to the country and people, willing to be a stable national energy security "fuse" and economic stability of the "ballast stone ", several generations of oil workers unswervingly dedicated to this grand goal of youth and talent. But changing the single structure of economic industry to realize economic transformation and development is a must-do answer question in Daqing city. In the new era, with the change of the international situation and the increase of the downward pressure of the economy, it is the trend of the times to adjust the structure and remove the production capacity. On the basis of consolidating the economic foundation of oilization, we should vigorously develop the non-oil economy, especially the ten "wild goose array" industrial plates represented by new energy, new materials, automobile manufacturing and electronic information. The direction of economic transformation is bound to develop high-tech emerging industries, and need high-tech complex talents. Therefore, talent is the fundamental factor to ensure the realization of economic transformation and high quality development in Daqing City, without the talent with equal emphasis on quantity and quality as the foundation, the economic transformation and development is the wood without source water.

Puting the development of human resources in the top priority of scientific and technological innovation, because people are the most active factor in productivity and the most critical factor in scientific and technological innovation .The so-called "cover the extraordinary merit, must treat the extraordinary person." [5] Population is the foundation of urban development, talent is the core driving force of economic development and the most creative factor of production. Whether a city can gather certain talents, the key depends on whether the city has rich historical background and sustainable development potential. Although Daqing City was built soon, just after "forty no doubt ", but just a few decades accumulated deep inside information, but also a vibrant city. Daqing's unique charm needs to be excavated, summarized and publicized, so that the "truth, goodness and beauty" of Daqing City can be known by more people, attract more talents to gather in Daqing, and build a "new Daqing ".

Daqing has 6 colleges and universities ,4 undergraduate colleges and 2 colleges and universities, of which 2 colleges and universities recruit students, which constitutes the pattern of "four universities and four colleges" in Daqing. In 2019, there were 193300 college graduates in Heilongjiang Province and nearly 14000 college graduates in Daqing, after 139200 in Harbin, accounting for $7.12 \%$ of the total number of graduates in the province. Daqing city has abundant 
higher education resources and great talent training potential, which can provide guarantee for the completion of Daqing talent introduction plan and support Daqing city to take the road of high quality development. Therefore, it is very necessary to carry out "Education proud of Daqing City" in Daqing City. On the one hand, Daqing City has sufficient higher education resources and the scale of college students. On the other hand, Daqing City should make full use of its talent resources so that the graduates of these colleges and universities can be used by themselves.

\subsection{The direct motivation for carrying out "Education proud of Daqing city" is to complete the talent introduction plan and reverse the serious outflow of college graduates in Daqing}

On September 29, 2019, the Organization Department of the CPC Daqing Municipal Party Committee issued the Implementation Plan for the Regular Introduction of Talents in Colleges and Universities in Daqing City (hereinafter referred to as the Plan). The Programme sets out two mission objectives, one of which is to attract the concentration of university graduates, namely, the planned introduction of 60,000 college graduates from 2019 to 2021, of which 15,000 are from Daqing; and the goal of 30,000 college graduates annually by 2025.The program fully demonstrates the determination and strength of Daqing in the work of introducing talents, and is an important measure of the strategy of strengthening the city with talents. Its purpose is to "attract more outstanding talents to celebrate the officers to start a business, and to provide a strong talent guarantee for Daqing's transformation and development and high quality development".

There are 6 colleges and universities inDaqing, and the total number of graduates of these six colleges and universities in 2017-2019 is 11759,10970,5604,7216,3162 and 2720 respectively; in three years, the total number of graduates of 6 colleges and universities is 13770 in 2017,13889 in 2018 and 13772 in 2019, with an average annual number of graduates of 13810.Is abundant talent resources transformed into the motive force of Daqing city's economic transformation and development? In order to find out this problem, the author did a research on employment entrepreneurship of college graduates in Daqing in 2019. According to the survey data, the outflow of graduates from universities in Daqing is very serious.

In 2017, a total of 1447 college graduates stayed in Daqing for working, accounting for $10.51 \%$ of the 13770 graduates in that year; while only 1135 of the 1497 Daqing graduates chose to work in Daqing City, a loss of 362, the loss ratio was 24.2\%. In 2018, a total of 905 people stayed in Daqing for working in six colleges and universities, accounting for 6.52 percent of the 13889 graduates that year, a decrease of four percentage points from 2017; while only 740 of the 1092 Daqing graduates chose to work in Daqing City, a loss of 352, the loss ratio of 32.2 percent. In 2019, a total of 732 people from 6 colleges and universities stayed in Daqing for working, accounting for 5.32\% of the 13772 graduates of that year, a drop of 1.2 percentage points, while only 556 of the 843 Daqing graduates chose to work in Daqing City, a loss of 287 , the loss ratio was 34\%.

The author also carries on the employment intention survey to the pre-graduation students in 6 colleges and universities in Daqing in 2020 through the "questionnaire star ".A total of 1587 students participated in the survey, and these students came from 106 majors, which basically covered the majors opened in Daqing University. More than $50 \%$ of the respondents chose direct employment, while $44.8 \%$ chose to pursue further studies, indicating that nearly half of the students were still waiting for postgraduate studies or graduate studies. In terms of employment intention cities, only $7.06 \%$ chose to stay in Daqing after graduation. Forty-seven percent of the respondents thought they were "very suitable for development in Daqing ", and nearly 60 percent said they were not suitable for development in Daqing. More than 80 percent of the respondents thought that the economic development level and potential of the cities affected the employment choice of graduates, followed by the living environment and housing, which were closely related to the cost of living. In 
terms of understanding the employment entrepreneurship policy in Daqing City, more than 50\% of the respondents chose not to understand the employment entrepreneurship policy in Daqing City.

\section{Conclusion}

It should be said that it is not difficult to see from these groups of data that the loss of college graduates in Daqing is very serious. There are many reasons for this phenomenon, but the most direct reason is the lack of recognition of Daqing graduates and lack of confidence in Daqing's economic development. Therefore, it is urgent to carry out the special education activities of "Education proud of Daqing City ".

The local government is the leading department of "Education proud of Daqing City " activities, and should issue relevant educational program or method on the basis of extensive consultation, promote the effective development of "Education proud of Daqing City " as a whole, and form a good atmosphere of loving Daqing, building Daqing and devoting themselves to Daqing in the society.

\section{Acknowledgements}

Daqing Philosophy and Social Sciences Planning Key Research Project "Research on the Countermeasures of College Students Staying in Daqing for Employment and Entrepreneurship from the Perspective of High Quality Development", Project No. DSGB2019010.

\section{References}

[1] Shiying Zhang. Daqing Year Looking Back at Daqing Spirit, October 7, 2019, https://www.xuexi.cn/lgpage/detail/index.html? id=8776625124296338692.

[2] Daqing 2019 government work report. http://www.daqing.gov.cn/zfgz/zfgzbg/615900.shtml.

[3] lihua Han, Zhonghua He. A reporter's transcript: http://www.sohu.com/a/332585975_161051.

[4] Eastern Han Dynasty, Bangu. Han Shu Wu Di Ji 6.

[5] Daqing three years will introduce 60,000 college graduates. http://www.daqing.gov.cn/zwdt/qszwxx/643791. shtml. 